\title{
Capital Budgeting In Practice: Issues Not Addressed In Finance Texts
}

Patty Hatfield, (E-mail: patty@bradley.edu), Bradley University Donna Hill, (E-mail: donna@bradley.edu), Bradley University

Philip Horvath, (E-mail: hap@bradley.edu), Bradley University

\begin{abstract}
Undergraduate and graduate finance textbooks present the capital budgeting process as a formal quantitative process. Absent from this model is any meaningful discussion of the role of qualitative factors in long-term investment analysis. Our findings reveal that for most firms, the conventional textbook approach to capital budgeting is not practiced in the business world. We find that qualitative factors play a critical, and in many cases, a dominant role in the capital budgeting process. The purpose of this paper is to help instructors provide guidance for students in understanding the way quantitative and qualitative capital budgeting tools are actually used in practice. This knowledge will help students use these skills much more effectively and allow them to successfully integrate themselves into a company's capital budgeting process. Furthermore, this understanding will help the student bridge the gap between education and practice.
\end{abstract}

\section{INTRODUCTION}

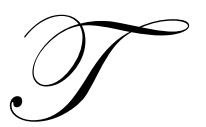

ypically in a finance curriculum there are courses that either deal exclusively with the topic of capital budgeting or advanced corporate finance courses that include a large capital budgeting component. The current finance textbooks [Brealey and Myers (2003), Seitz and Ellison (2004), Brigham and Daves (2004), Brigham and Ehrhardt (2005)] on the market typically present the capital budgeting process as a formal quantitative process moving through a series of formal normative stages. The existing theoretical framework suggests that managers forecast the free cash flow of a project and then apply sophisticated capital budgeting techniques such as the net present value (NPV) or the internal rate of return (IRR) to evaluate the cash flows. Sensitivity, scenario, and simulation analysis are also used to assess the degree of risk associated with the project. The discount rate is then adjusted or certainty equivalent cash flows are forecasted to accommodate the risk of the project. Students also learn the importance of evaluating projects of unequal lives in order to make them comparable to other projects being considered and learn to evaluate some projects in an option-pricing framework. Invariably, the end result is a thorough quantitative analysis that leads to the selection of those projects that add the greatest value to the firm.

Research conducted over the past 28 years [Gitman and Forrester (1977), Schall, Sundem and Geijsbeek (1978), Klammer and Walker (1984), Klammer, Koch and Wilner (1991), and Kim, Crick and Kim (1986), Bierman (1993), and Farragher, Kleiman and Sahu (1999)] report that firms have become increasingly sophisticated in their quantitative analysis of capital budgeting decisions. These studies indicate that firms have increased their utilization of discounted cash flow capital budgeting methods while still employing the more traditional methods including the payback and average rate of return. Thus, it would be easy to infer that over the last three decades the divergence between practice and theory regarding capital budgeting practices has narrowed significantly.

While this may be true with regard to the understanding of capital budgeting techniques, noticeably absent from this model and current finance textbooks is any meaningful discussion of the role of qualitative factors in longterm investment analysis. Yet there exists a stream of research indicating that in practice qualitative factors may be at least as important in the capital budgeting process than the quantitative factors prescribed by financial theory. For example, Pike (1983) found that there were indeed a number of qualitative factors significant in the capital budgeting process. His findings suggest that managers attach almost the same degree of importance to qualitative factors as they 
do quantitative factors. More recently, a study of 118 U.S. manufacturing firms by Hatfield, Goitein, Horvath and Webster (1997) found that in addition to sophisticated capital budgeting techniques, a number of subjective measures were used in the capital budgeting process. A study by Hatfield, Hill and Horvath (1999) further suggests that qualitative factors are used to "package" a project so that it can pass through the next checkpoint in the approval process. The results of these studies imply that while the gap between education and practice has narrowed in one area of capital budgeting, a new divergence is revealed. That is, qualitative factors seem to play a critical role in the capital budgeting process. Perhaps, in many cases, even more critical than quantitative factors.

The purpose of this paper is to provide guidance for students in understanding the way classic capital budgeting tools are used in practice. This knowledge will help them use these skills much more effectively while also helping them bridge some of the differences in practice and education. Our findings reveal that the capital budgeting process used in practice is a significant departure from that described in the classroom. We suggest that, for most firms, the conventional textbook approach to capital budgeting is not being practiced in the business world. Students armed with the knowledge of theory driven financial procedures along with an understanding of the qualitative processes that are used will be much better prepared to integrate themselves into the process while helping to bridge the gap between education and practice.

\section{SAMPLE AND METHODOLOGY}

A series of focus groups were conducted that inquired into the capital budgeting processes used by the sample firms. Six firms of varying sizes and representing different industries provided focus group participants. Three of these firms were heavy manufacturing firms with production and administrative facilities around the globe. One firm was involved in heavy manufacturing with international sales and distribution activities. Two firms were light manufacturing companies with international sales and distribution. The sixth firm was a regional credit union. All firms had headquarters and/or a major presence in the Midwest.

There were a total of 46 participants in the focus groups. All of the participants were either middle or upperlevel management and had major responsibility or "sign-off" authority on capital projects. When necessary, focus group members were divided by hierarchy so that middle-level managers could discuss their processes freely without higher-level managers present. The participants represented a wide variety of line and staff functions. The focus group session was designed to be two hours in length and consisted of short, easily answered questions probing their capital budgeting processes. At the end of the focus group session, a brief open-ended questionnaire was distributed that solicited responses with regard to their position, education, experience and their assessment of the ranking of the most important characteristics in the capital budgeting process as a project moves through the various "sign-off" stages.

\section{DISCUSSION OF FINDINGS}

\section{Project Categorization}

In the classroom, the capital budgeting process is presented as evaluating a stream of projects to find those that add the most value to the firm without discriminating between project types. However, we find that all of the firms in our study categorize projects by project types. Certain project types or categories are evaluated differently than others. Some categories receive preference over others while some are automatically accepted without any formal financial analysis. All firms in our study indicated that projects that improved safety were automatically approved. Other categories also receive automatic approval by some firms. For example, one of the participants in a focus group stated, "maintenance projects do not require an economic return....quality typically would not either. On the other hand, a significant process improvement might in fact require an economic return." The rationale is that if companies are deficient in any of these areas then they have no choice other than to invest or they will lose customers. Another focus group participant indicated they gave automatic approval of maintenance, quality and safety projects. They defended this by saying, "I believe we all share the same common ground belief that if we solve the first two [customer satisfaction and employee satisfaction], the last one [financial satisfaction] will just happen." 
Another project category that gained automatic approval for all of our focus group firms was small projects. The cutoff for small projects varied from firm to firm. One focus group explained that their small project cutoff was $\$ 10,000$ while it was $\$ 50,000$ for another firm. One focus group described a strategy used to obtain automatic approval of a large project. This group would slice a larger project into " $\$ 10,000$ pieces" so that they could automatically invest and not have to go through an approval process. A focus group from another company explained that "a great majority of the projects are in the $\$ 5$ to $\$ 10$ thousand dollar range" and these small projects received automatic approval.

\section{Project Origination}

Consistent with what is taught in the classroom, the results of our study suggests that projects originate from a variety of sources. Project proposals arise from customers, suppliers, competitive forces, trade magazines and capital equipment shows. Many projects, such as replacement, capacity, quality and safety tend to originate from the lower-level managers. Larger, strategic type projects originate from both upper-level and lower-level management.

In all of our groups, projects that originate from upper-level management tended to be automatically accepted. Our focus groups also show that occasionally financial analysis is done for these projects after it has already been accepted as a means to communicate the proposal to lower levels of the organization. Furthermore, it was expressed that this also served the purpose of building consensus regarding project support. One focus group participant explained that even if the project is not financially justified, assumptions may actually be altered to make the project appear acceptable. The results of this analysis are then used as a marketing tool to help build support for the project. As one person stated, "If you have the top person saying it [the project] is worth it, then we tend to show that it is."

\section{Process}

The participants in the focus group indicated that most projects are either accepted or rejected just after the preliminary appropriation request is submitted. For example, group members indicated that when the company was formulating the capital budget for the year, projects were selected at that time for inclusion in the budget even though a formal analysis had not yet been performed. At this stage a preliminary appropriation request is submitted that discloses the major characteristics of the project, such as the cost, the estimated payback and the rationale for its purchase. We find that it is at that point most projects are either accepted or rejected. Those that are rejected are eliminated and those that survive this checkpoint and are not categorized as an automatic investment go through a more formal evaluation involving a hierarchical sign-off process. At this stage, the firms in our survey put together teams of individuals to collect data for the evaluation. The purpose of the teams is to encourage buy-in of the project and they generally include people from a variety of cross-functional areas. Also during this time, several of the firms noted that if the project is being initiated from the lower levels of the company, it is important to try to find a sponsor for the project to help ensure that it passes through all of the checkpoints. The sponsor in many cases may be an upper-level manager that values the project or it may be a lower-level manager that has experience and success in getting proposals approved. The team pulls all the data together and puts together a more detailed project appropriation request that is presented at each of the hierarchical checkpoints. The number of checkpoints that a project must go through is directly related to the size of the project and the size of the firm. For most firms, it is at this stage of the process that the financial analysis occurs. Interestingly, half of the firms that we interviewed use discounted cash flow methods while the others just calculate the payback.

\section{Background Of The Individual(S) That Authorize Project Proposals}

The information gathering process for project approval is somewhat dependent on the type of information valued by the individual(s) that must sign off on the project. As the proposal passes through the checkpoints or gates, different information is emphasized. For example, if an accountant must sign off, then financial analysis is likely to be important. If a marketing person must sign off, then perhaps information showing the benefits to the customer may be more critical. Project proposals are clearly "packaged" to complement the information valued by the individual manning the checkpoint. Furthermore, our findings suggest that for most firms the financial analysis becomes most 
important at the highest-level checkpoint. Earlier checkpoints are typically more concerned with tooling, maintenance, labor and other issues. By the time a project makes it to the last checkpoint it is almost never rejected. Projects are most likely to be rejected early in the process, generally before much financial analysis is done.

The process described above is a key departure from what is taught in the classroom. Students learn that formal financial analysis is performed on all projects and decisions regarding whether or not to invest are based on those results. However, in our study most projects are accepted or rejected before any financial analysis is performed. Participants clearly recognized and expressed that if they want to push an investment through the process, it is important to get it included in the capital budget first. Once it passes through that hurdle it has a high probability of getting through the others.

\section{Timing Of Project Proposals}

The capital budget is typically determined at the beginning of the fiscal year. During this time project proposals are solicited to be included in the budget. Managers make an effort to present project proposals at the time the capital budget is being determined. Projects that are proposed after the current capital budget is approved are more likely to be postponed to the next year's capital budget. Our focus group participants indicated that the managers' only opportunity to get the project included in the current year's budget is to show that the project is of an automatically approved category, or that the financial return is attractive enough to make the investment. If the return proves to be attractive, then additional money would have to be raised to fund the project or a previously approved project would have to be postponed from the current budget. As a result, these "late" project proposals must be subjected to more formal financial analysis and prove themselves to be valuable in order to gain the support of upperlevel management to be included in the budget. Thus, a company may need to reduce expenditures on process and quality in order to spend on capacity. For example one firm presented the following scenario, "we're spending too much too quickly, we must slow it down even though we have factory mangers who say, 'wait a minute, I've got this in the budget and I want to do this.' Yeah, we don't disagree, but the reality is we don't have all the cash available to be able to do everybody's projects all at one time."

\section{CONCLUSIONS}

The "big picture" revealed in each of the focus group interviews is that the capital budgeting process is largely a selling effort. Furthermore, in most cases, a proposal's acceptance or rejection is a foregone conclusion before any financial analysis is performed. Participants indicate that after the proposal is accepted in the budget then information is collected with the intent to address questions that may arise as the project moves through each checkpoint. The information that is relevant at each checkpoint varies from firm to firm based on the background of the individual(s) manning the checkpoint. However, the team that is backing the project will try to anticipate these concerns so they can be successfully addressed. This may explain why those people that have experience in the company's capital budgeting process are more successful in getting projects approved. They can better anticipate what information is most relevant at each of the checkpoints.

Many of our focus group participants mistakenly felt that their project decisions were financially motivated even though there was no formal analysis. For example, they explained that if they do not provide for capacity or improve quality or safety then they may lose the customer, thereby losing revenues. However, what they may fail to see is that through formal analysis they may uncover alternatives that would serve them better in the long run. Rather than adding another lathe to meet the increase in demand, there may be other alternatives that would serve them better such as outsourcing excess demand until another facility is built, or acquiring another business to support the rapid growth. The current methods solve the problems in the short-run but encourage "business as usual" when innovation may be a better long-term solution. Furthermore, rather than increase existing capacity, each investment should be evaluated to make sure that the firm's money is being put toward its most productive use. Every investment has opportunity costs that should be considered. 
In summary, a closer view of the data reveals factors that appear to be most important in the project approval process:

1. Project Categorization

Project categorization was the most important criteria for project acceptance for almost all of the firms in our study. Certain project types, such as quality, maintenance and safety projects were largely exempt from formal analysis and were automatically invested without formal financial analysis. Small projects also tend to be automatically accepted, although there is not a universal definition of "small."

2. Project Origination

Projects that are generated from top levels of management generally do not have to be justified financially. Projects generated from lower levels of the firm take longer to pass through and are subject to more qualitative and perhaps, quantitative scrutiny.

3. Background of the Individual(s) That Must Sign-Off On the Project

Project proposals are clearly "packaged" to complement the information valued by the individual manning the checkpoint.

4. Timing of the Proposal

Proposals brought forth during the construction of the capital budget generally do not undergo the level of scrutiny as those projects that seek approval after the budget has been determined.

\section{CLASSROOM EXERCISE}

The discussion of these processes is critical in giving finance students a thorough understanding of the capital budgeting practices used by firms and allowing them to integrate themselves into the process. This is particularly important for the exceptional student that may find him/herself thrust into this process at an early stage of him/her career. Understanding this process clearly places the graduate in an advantageous position through enhanced understanding and appreciation of the internal practices involved while integrating quantitative analysis.

Describing the differences between practice and theory can generate some lively class discussion. One way to illustrate this idea is by role-playing. The professor can ask students to assume the role of a lower-level manager working for a firm that sells lighting solutions for business offices. One particular lighting solution that this manager had championed has been very successful and has been installed in many offices throughout the United States. You, the manager, have done much research analyzing lighting designs used in European business offices. You feel that your solutions would be a significant improvement for many of these companies. As a result, you have assembled a team of engineers and sales staff to derive costs and sales estimates of expanding into European markets. When the cash flow estimates are completed, you carefully check the assumptions used to derive these cash flows and feel that they are conservative. After running the numbers, you find that the payback is 5 years (the average payback for the company is 3 years), the net present value is $\$ 25.5$ million and the internal rate of return is $30 \%$ against a $14 \%$ risk adjusted hurdle rate. Even though the numbers look attractive, you know that you would have to gain the support of three managers that must sign off on the project. Given the type of project, it will not be too difficult to obtain the buy-in of the first two managers. Gaining the approval of the third manager could present quite a challenge.

At this point, the professor can choose three students to represent each of the three higher-level managers that must sign-off on the project if it is to be included in the capital budget. Each student should receive instructions as to the criteria they see as being the most important. Based on this information, the "manager" can ask questions regarding the project. 
The first manager is relatively new to the company so you know very little about him. You find that he has a degree in accounting and his most recent position was as controller for a smaller company. The second manager has been with the company for 15 years and you know her well. You know that she tends to favor projects that have longterm benefits. Her focus is adding long-term value to the company.

The third manager that must sign off is the CFO and is well respected within the company for his conservative views that have served the company well. His mantra is that "we must continually focus on quality and design improvements that can be made in our current market. Trying to expand into new markets would only divert our attention from our current market and give our competitors a perfect chance to steal our market share." This philosophy has served the company well and you realize that it could be very tough to get his support.

The professor can then ask the rest of the class to assume that they are a lower level manager that is convinced that this project is very valuable to the firm. They know that in order to gain approval to invest in this project, they must obtain the support of the three managers above them. If they were that manager, how would they try to gain approval at each sign off?

Obviously, the suggestions will vary, but a lively class discussion should certainly take place. Students may suggest that since the first manager has an accounting background, then he is more likely to be impressed by the numbers. However, a payback of 5 years indicates that this project will take some time to generate a return. Since you are unsure whether this manager favors quick payback projects or is willing to wait for returns, it may be best to emphasize the profitability in terms of the IRR and the NPV. You could accomplish this by sharing the underlying assumptions used in the cash flow estimates. This may help draw the manager's attention to the potential profitability of the project and detract a bit from the payback.

It is probably easiest to obtain support from the second manager. This project is quite long-term in nature and naturally displays a strategic emphasis. Again, the presentation should focus on the long-term value added to the company. This manager is less likely to be offended by the payback. This manager will also appreciate the underlying assumptions that went into the cash flow estimates and may be somewhat pleased that the results are conservative. Thus, the long-term value may be significantly higher.

Acceptance by the third manager will certainly be the most difficult to attain. One possibility is to frame the project as benefiting our current customers. For instance, the knowledge required to compete in foreign markets will allow us to learn more about quality and design issues. It could help us track new technologies that could be developed elsewhere and bring it to our domestic markets before another firm does. As some of our domestic customers expand internationally they can continue to come to us for designs that would be attractive in their subsidiary offices. Adopting procedures, technologies and products discovered abroad can improve our competitive position in our domestic market.

We can conclude by acknowledging that in practice it appears that financial analysis is largely used as a method to achieve a consensus for the project proposal. The role-playing tool is an excellent way to emphasize that point. However, the overriding lesson in the demonstration comes from the discussion that follows. The professor should ask the class what potential problems exist with this approach to capital budgeting? Some companies have done well following this process, how can one argue with that? A discussion of capital rationing and the importance of putting financial resources in the most profitable ventures should ensue. Another issue to discuss is the agency problems inherent in the practice. The one advantage in the process is consensus building. While consensus is important, the student that understands practice and theory is in a position to successfully capture a supervisor's attention using qualitative factors while also emphasizing the financial superiority of the project. In other words, students that understand the selling process and appreciate the importance of financial theory in maximizing firm value have an opportunity to help bridge the gap between theory and practice that exists today. 


\section{REFERENCES}

1. Bierman, H. (1993) Capital Budgeting in 1992: A Survey, Financial Management, (Autumn), 24.

2. Brealey R. and S. Myers, 2003, Principles of Corporate Finance, Seventh Edition, New York, NY, McGrawHill.

3. Brigham E. and P. Daves, 2004, Intermediate Financial Management, Eight Edition, Mason, OH, Thomson, South-Western College Publishing.

4. __ and M. Ehrhardt, 2005, Financial Management: Theory and Practice, Eleventh Edition, Mason, OH, Thomson, South-Western College Publishing.

5. Farragher, E. J., R. T. Kleiman, and A. P. Sahu (1999) Current Capital Investment Practices Investment Practices, The Engineering Economist, v44 No 2, 137-150.

6. Gitman, L. and J. Forrester (1977) A Survey of Capital Budgeting Techniques Used by Major U.S. Firms, Financial Management, (Fall), 66-76.

7. Hatfield, Patty, B. Goitein, P. Horvath, and A.Webster (1996) Financial Criteria, Capital Budgeting Techniques, and Risk Analysis of Manufacturing Firms, The Journal of Applied Business Research, Vol. 13, No. 1 (Winter), 95-104.

8. Haka, S., L. Gordon, and G. Pinches (1985) Sophisticated Capital Budgeting Techniques and Firm Performance, The Accounting Review, (October), 651-669.

9. Hatfield, Patty, D. Hill, and P. Horvath (1999) Industrial Buying and Divergence of Capital Budgeting Theory and Practice: An Exploration, Journal of Applied Business Research, Vol. 15, No. 1, (Winter), 37-46.

10. Kim, S. (1982) An Empirical Study on the Relationship Between Capital Budgeting Practices and Earnings Performance, Engineering Economist, (Spring), 185-196.

11. T. T. Crick, and S. H. Kim, (1986) Do Executives Practice What Academics Preach? Management Accounting, (November), 49-52.

12. Klammer, T. (1978) The Association of Capital Budgeting Techniques and Firm Performance, The Accounting Review, (April), 353-464.

13. _ B. Koch, and N. Wilmer (1991) Capital Budgeting Practices - A Survey of Corporate Use, Journal of Management Accounting Research, (Fall), 447-464.

14. and M. Walker (1984) The Continuing Increase in the Use of Sophisticated Capital Budgeting Techniques, California Management Review, (Fall), 137-148.

15. Pike, R. (1983) Sophisticated Capital Budgeting Systems and Their Association with Corporate Performance, Managerial and Decision Economics, Vol. 5, No. 2, 91-97.

16. Shall, L. D., G. L. Sundem, and W. R. Geijsbeek, Jr., (1978) Survey and Analysis of Capital Budgeting Methods, Journal of Finance, Vol. 33, No. 1, 281-287.

17. Seitz, N. and M. Ellison, 2004, Capital Budgeting and Long-Term Financing Decisions, Fourth Edition, Mason, OH, Thomson, South-Western College Publishing. 


\section{NOTES}

